ARTICLE

DOI: 10.1038/s41467-018-06242-w

\title{
Selective reduction and homologation of carbon monoxide by organometallic iron complexes
}

Helen R. Sharpe (1,3, Ana M. Geer ${ }^{1}$, Laurence J. Taylor (1) ${ }^{1}$, Benjamin M. Gridley ${ }^{1,4}$, Toby J. Blundell,

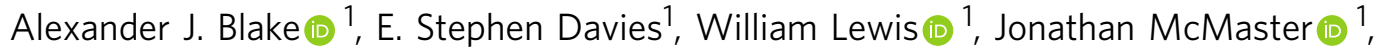
David Robinson (1) ${ }^{2} \&$ Deborah L. Kays (D) ${ }^{1}$

Carbon monoxide is a key $\mathrm{C}_{1}$ feedstock for the industrial production of hydrocarbons, where it is used to make millions of tonnes of chemicals, fuels, and solvents per annum. Many transition metal complexes can coordinate $\mathrm{CO}$, but the formation of new $\mathrm{C}-\mathrm{C}$ bonds in welldefined compounds from the scission and subsequent coupling of two or more $\mathrm{CO}$ moieties at a transition metal centre remains a challenge. Herein, we report the use of low-coordinate iron(II) complexes for the selective scission and homologation of $\mathrm{CO}$ affording unusual squaraines and iron carboxylates at ambient temperature and pressure. A modification of the ligand framework allows for the isolation and structural characterisation of a proposed metallacyclic Fe(II) carbene intermediate. These results indicate that, with the appropriate choice of supporting ligands, it is possible to cleave and homologate carbon monoxide under mild conditions using an abundant and environmentally benign low-coordinate, first row transition metal.

\footnotetext{
${ }^{1}$ School of Chemistry, University of Nottingham, University Park, Nottingham NG7 2RD, UK. ${ }^{2}$ Department of Chemistry and Forensics, School of Science and Technology, Nottingham Trent University, Nottingham NG11 8NS, UK. ${ }^{3}$ Present address: School of Chemistry, The University of Manchester, Oxford Road,

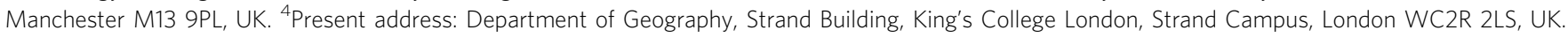
Correspondence and requests for materials should be addressed to D.L.K. (email: Deborah.Kays@nottingham.ac.uk)
} 
C $\mathrm{O}$ activation is a critical reaction in organometallic chemistry, where it can be used to form valuable organic compounds through both homogeneous and heterogeneous catalytic transformations. These include carbonylation, hydroformylation, polymerisation, hydroesterification, and syngas conversion ${ }^{1-3}$. Early investigations of homogeneously catalysed CO hydrogenation and oligomerisation required the use of prohibitively high temperatures and pressures, affording only simple oligomers in low yield ${ }^{3}$. This can be improved somewhat through the use of additives such as Lewis acids, Lewis bases, or Brønsted acids. The study of model systems such as $\left[\left(\eta^{5}-\mathrm{C}_{5} \mathrm{H}_{5}\right) \mathrm{Fe}\right.$ $\left.(\mathrm{CO})_{3}\right]^{+}$, aided by the addition of reducing agents and Lewis base, allowed the fundamental steps in these processes to be elucidated $^{4-7}$. Such electron-rich systems, however, are unable to undergo facile carbonylation; requiring borohydrides for carbonyl reduction and the use of relatively strong electrophiles to release homologated products ${ }^{3}$.

The literature is replete with examples of migratory insertion of $\mathrm{CO}$ into $\mathrm{M}-\mathrm{C}$ bonds. Of particular note is the reduction of coordinated $\mathrm{CO}$ by insertion into $\mathrm{M}-\mathrm{H}$ and $\mathrm{M}$-alkyl bonds, resulting in formyl or acyl species respectively, where the formal oxidation of the ligand permits the reduction of $\mathrm{CO}^{7,8}$. Acyl intermediates can act as a precursor for the formation of $\mathrm{C}_{2}$ species and higher oligomers. Alternatively, the coupling of $\mathrm{CO}$ with carbenes forming $\eta^{2}$-ketene complexes provides another route to $\mathrm{C}-\mathrm{C}$ bond formation ${ }^{9,10}$. More interesting still is the chemistry reported for several zirconium complexes, where $\mathrm{CO}$ is not only inserted into the $\mathrm{M}-\mathrm{H}$ bond, but the reductive coupling of two or more $\mathrm{CO}$ molecules has been reported ${ }^{11-14}$. Although the reductive coupling of $\mathrm{CO}$ remains unusual, there are a number of examples from across the periodic table, including the p-block ${ }^{15,16}$, d-block ${ }^{12,17-26}$ and f-block ${ }^{27-34}$.

The scission and homologation of CO to generate synthetically useful compounds under mild conditions remains a significant challenge. The $\mathrm{C} \equiv \mathrm{O}$ bond is the strongest bond in chemistry ( $\mathrm{CO}$ bond dissociation energy $\left.=1076 \mathrm{~kJ} \mathrm{~mol}^{-1}\right)^{35}$ and the complete cleavage of $\mathrm{CO}$ requires six electrons for reduction. However, complexes of the d-block and f-block elements have been shown to form a range of compounds through mechanisms involving the complete scission of $\mathrm{C} \equiv \mathrm{O}$ followed by homologation ${ }^{12,36-44}$. Previous work on $\mathrm{C}_{4}$ ring formation via $\mathrm{CO}$ activation has yielded squarates $\left(\mathrm{C}_{4} \mathrm{O}_{4}{ }^{2-}\right)$ from uranium complexes, which does not require the scission of $\mathrm{C} \equiv \mathrm{O}$ bonds ${ }^{27}$.

The reductive coupling and cleavage of $\mathrm{CO}$ is unknown for low-coordinate iron species ${ }^{45,46}$, with early studies indicating that CO coupling was promoted by high-coordinate transition metal complexes $^{47}$. Furthermore, previously reported reactions between transition metal $m$-terphenyl complexes and $\mathrm{CO}$ afforded only insertion products such as acyl complexes ${ }^{48,49}$ and sterically encumbered ketones ${ }^{50}$.

Herein, we report the complete scission of $\mathrm{C} \equiv \mathrm{O}$ by lowcoordinate $\mathrm{Fe}^{\mathrm{II}}$ complexes at ambient temperature and pressure, accompanied by the formal oxidation of the terphenyl ligand, affording unusual 1,3-squaraines through $\mathrm{C}-\mathrm{C}$ coupling reactions with concomitant formation of $\mathrm{Fe}^{\mathrm{II}}$ carboxylate complexes and $\mathrm{Fe}(\mathrm{CO})_{5}$. These squaraine species feature broken conjugation (resulting in atypical electronic and bonding properties) and represent the first examples of $\mathrm{C}_{4}$ ring formation from $\mathrm{CO}$ involving complete cleavage of the $\mathrm{C} \equiv \mathrm{O}$ bond.

\section{Results}

Reactions between iron diaryl complexes and carbon monoxide. Exposure of a toluene solution of $\mathbf{1}^{\text {Mes } 51}$ or $\mathbf{1}^{\mathrm{Xyl}}$ to excess $\mathrm{CO}$ at ambient temperature and pressure (Fig. 1a) results in an immediate colour change from yellow to red; further stirring for
6 days $\left(\mathbf{1}^{\text {Mes }}\right)$ or $36 \mathrm{~h}\left(\mathbf{1}^{\mathrm{Xyl}}\right)$ under a CO atmosphere forms a dark red suspension. Recrystallisation from hexane at $-30{ }^{\circ} \mathrm{C}\left(1^{\mathrm{Mes}}\right)$ or the layering of pentane onto a toluene solution at room temperature $\left(\mathbf{1}^{\mathrm{Xyl}}\right)$ affords red crystals of the squaraine molecules $2^{\text {Mes }}$ and $2^{\text {Xyl }}$ suitable for single crystal X-ray diffraction. The molecular structures of $2^{\text {Mes }}$ and $2^{\text {Xyl }}$ feature a central fourmembered ring $\left\{\mathrm{C}_{4} \mathrm{O}_{2}\right\}$ with $m$-terphenyl substituents bound to each side (Fig. $1 \mathrm{~b}$ and Supplementary Fig. 2). Selected bond distances and angles for $2^{\text {Mes }}$ and $2^{\text {Xyl }}$ can be found in Table 1.

In contrast to other aryl-substituted squaraines, where the aryl rings typically lie in-plane with the $\mathrm{C}_{4} \mathrm{O}_{2}$ ring to maximise conjugation (average dihedral angle between aryl ring and $\mathrm{C}_{4} \mathrm{O}_{2}$ ring $\left.=1.24^{\circ}\right)^{52}$, the aromatic rings in $2^{\mathrm{Mes}}$ and $2^{\mathrm{Xyl}}$ are twisted out of plane with the central ring [ $2^{\text {Mes }}$ : $56.38(13)^{\circ}$ and 51.71 $(11)^{\circ}, 2^{\mathrm{Xyl}}: 50.93(5)^{\circ}$ ]. This is likely due to the steric demands of the terphenyl substituents. The $\mathrm{C}-\mathrm{O}$ bond lengths in these compounds are also shorter than those found in typical

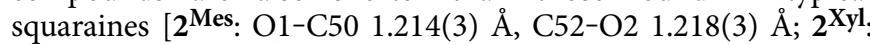
O1-C14 1.212(2) $\AA$; average squaraine $\mathrm{C}-\mathrm{O}$ bond length $=$ $1.24 \AA]^{52}$. This is indicative of greater $\mathrm{C}-\mathrm{O}$ double bond character, which is likely due to reduced conjugation with the aromatic substituents.

The Fe $\mathrm{II}^{\mathrm{II}}$ carboxylate complexes $\mathbf{3}^{\mathrm{Mes}}$ and $\mathbf{3}^{\mathrm{Xyl}}$ (Fig. 1a) are also formed in the reaction of $\mathbf{1}^{\text {Mes }}$ or $\mathbf{1}^{\mathrm{Xyl}}$ with $\mathrm{CO}$ and their solid-state structures have been confirmed by X-ray crystallography. The geometry around these Fe centres (Fig. 1c and Supplementary Fig. 3) is a distorted seesaw $\left[\tau_{4}=0.57\left(3^{\mathrm{Mes}}\right)\right.$ and $\left.0.54\left(3^{\mathrm{Xyl}}\right)\right]^{53}$, and results from the coordination of $\mathrm{Fe}$ by one terminal and two bridging carboxylate ligands in which the angles between the $\mathrm{FeO}_{2}$ planes defined by $\mathrm{O}^{\prime}-\mathrm{Fe} 1-\mathrm{O} 2$ and $\mathrm{O} 3-\mathrm{Fe} 1-\mathrm{O} 4$ are $46.634(3)^{\circ}$ and $40.94(13)^{\circ}$ for $3^{\mathrm{Mes}}$ and $3^{\mathrm{Xyl}}$, respectively. When one considers the balanced reaction scheme (Fig. 1a), it is important to mention that the formal oxidation of the ligand is essential for the reduction of CO. In the overall reaction, there is a net reduction of iron by four electrons and a net reduction of $\mathrm{CO}$ by four electrons, giving a total net reduction of eight electrons from the oxidation of the aryl ligands. The reaction between $\mathbf{1}^{\mathrm{Mes}}$ and $\mathrm{CO}$ was found to be near-quantitative, as determined by NMR integration against an internal standard (see Supplementary Methods). However, isolated yields were low due to difficulties in separating $2^{\text {Mes }}$ from $3^{\text {Mes }}$, as the compounds have similar solubility. Analogous attempts to quantify the reaction between $1^{\text {Xyl }}$ and CO by NMR spectroscopy were hampered by the precipitation of $2^{\mathrm{Xyl}} / 3^{\mathrm{Xyl}}$ mixtures (see Supplementary Methods).

Squaraine $2^{\text {Mes }}$ has been characterised by ${ }^{1} \mathrm{H}$ and ${ }^{13} \mathrm{C}\left\{{ }^{1} \mathrm{H}\right\}$ NMR, IR and UV/Vis spectroscopies and by mass spectrometry. The ${ }^{13} \mathrm{C}\left\{{ }^{1} \mathrm{H}\right\}$ NMR spectrum $\left[\mathrm{C}_{6} \mathrm{D}_{6}\right.$ solution, Supplementary Fig. 5(a)] contains peaks at $\delta_{\mathrm{C}} 269.7$ and $177.3 \mathrm{ppm}$, corresponding to the carbonyl (OCC) and the terphenyl-bound carbons in the $\mathrm{C}_{4} \mathrm{O}_{2}$ ring, respectively. The assignment of the chemical shift at $269.7 \mathrm{ppm}$ to the remarkably deshielded carbonyl (OCC) of $2^{\text {Mes }}$ is confirmed by ${ }^{1} \mathrm{H},{ }^{13} \mathrm{C}$-HMBC NMR spectroscopy [Supplementary Fig. 5(b)]. This, again, most likely results from the steric demands of the pendant terphenyl groups forcing the aryl ring to twist out-of-plane with the $\mathrm{C}_{4} \mathrm{O}_{2}$ ring, which results in less charge delocalisation. In addition, most squaraines possess a donor-acceptor-donor (D-A-D) configuration where charge is delocalised into the $\mathrm{C}_{4} \mathrm{O}_{2}$ ring ${ }^{54-57}$, a feature which is absent here. For example, squaraines with $N, N$-diarylanilino substituents display ${ }^{13} \mathrm{C}\left\{{ }^{1} \mathrm{H}\right\}$ NMR peaks for the $\mathrm{C}_{4} \mathrm{O}_{2}$ ring in the range of 160 to $185 \mathrm{ppm}^{58}$. Similarly, the solution IR spectrum of $2^{\text {Mes }}$ in toluene possesses a C-O stretch at $1673 \mathrm{~cm}^{-1}$ (Supplementary Fig. 12), which is at a higher frequency than typical squaraines (range 1594-1633 $\mathrm{cm}^{-1}$ ) $54,56,59$. 
a

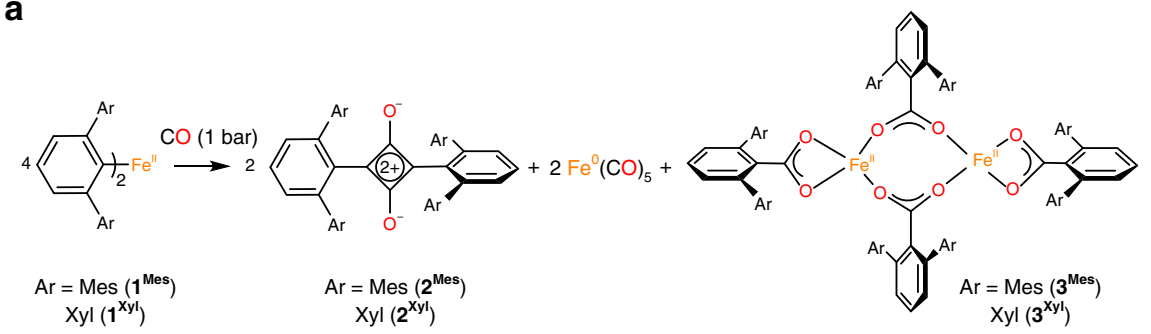

b

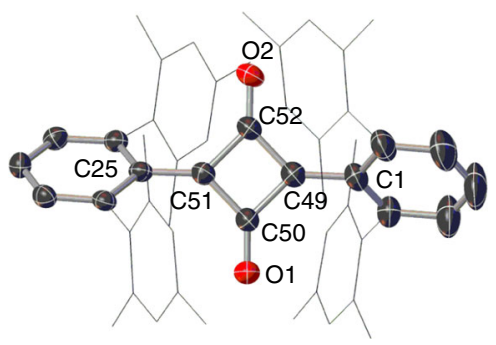

C

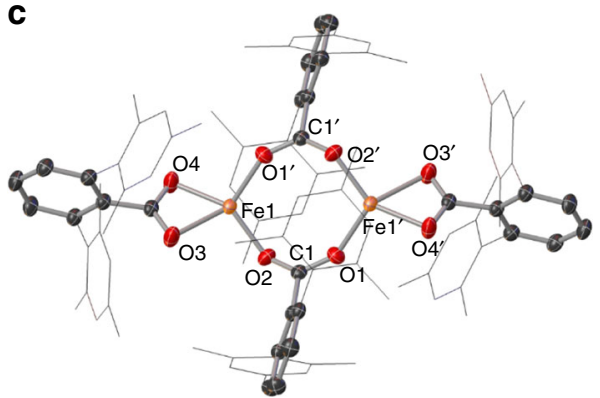

Fig. 1 The reductive coupling and functionalisation of CO by iron(II) diaryls $\mathbf{1}^{\mathbf{M e s}}$ and $\mathbf{1} \mathbf{X y l}$. a General scheme for the reaction between CO and iron(II) diaryls $\mathbf{1}^{\mathbf{M e s}}$ or $\mathbf{1}^{\mathbf{X y l}}$. $\mathbf{b}$ The molecular structure of $\mathbf{2}^{\mathbf{M e s}}$ with anisotropic displacement ellipsoids set at $50 \%$ probability. Mesityl groups shown as wireframe, hydrogen atoms and one molecule of hexane solvent are omitted for clarity. $\mathbf{c}$ The molecular structure of $\mathbf{3}^{\text {Mes }}$ with anisotropic displacement ellipsoids set at $50 \%$ probability. Mesityl groups shown as wireframe and hydrogen atoms have been omitted for clarity. Selected bond distances $(\AA)$ and angles $\left({ }^{\circ}\right)$ for

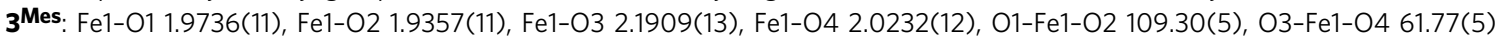

\begin{tabular}{|c|c|c|c|}
\hline & $2^{\text {Mes }}$ & $2^{X y 1}$ & $2 a$ \\
\hline O1-C50/O1-C14 & $1.214(3)$ & $1.212(2)$ & 1.213 \\
\hline $\mathrm{C} 52-\mathrm{O} 2$ & $1.218(3)$ & & 1.213 \\
\hline C49-C50/C13-C14 & $1.475(3)$ & $1.4837(18)$ & 1.472 \\
\hline C50-C51 & $1.470(3)$ & & 1.473 \\
\hline C51-C52 & $1.470(3)$ & & 1.473 \\
\hline C49-C52 & $1.472(4)$ & & 1.473 \\
\hline $\mathrm{C} 1$ plane $-\left\{\mathrm{C}_{4} \mathrm{O}_{2}\right\}$ & $56.38(13)$ & $50.93(5)$ & 47.38 \\
\hline $\mathrm{C} 25$ plane $-\left\{\mathrm{C}_{4} \mathrm{O}_{2}\right\}$ & $51.71(11)$ & & 47.38 \\
\hline
\end{tabular}

To gain insight into the structures of $\mathbf{2}^{\mathrm{Mes}}$ and $\mathbf{2}^{\mathrm{Xyl}}$, gas-phase DFT geometry optimisations were performed on a model compound of $\mathbf{2}^{\text {Mes }}$ and $\mathbf{2}^{\text {Xyl }}(\mathbf{2 a})$, in which the flanking mesityl and xylyl substituents were replaced by phenyl groups. Calculations for 2a give geometrical parameters (Table 1) that are in good agreement with those of the experimentally determined structures of $\mathbf{2}^{\mathrm{Mes}}$ and $\mathbf{2}^{\mathrm{Xyl}}$. Additionally, 2a features a nonplanar core with a dihedral angle between $\mathrm{C}_{4} \mathrm{O}_{2}$ ring and the aryl substituent of $47.38^{\circ}$, slightly smaller than those observed in $2^{\text {Mes }}$ and $2^{\text {Xyl }}\left[2^{\text {Mes: }} 56.38(13)^{\circ}\right.$ and 51.71(11) ${ }^{\circ}, 2^{\text {Xyl: }}$ 50.93(5) $\left.{ }^{\circ}\right]$. Squaraines have previously been isolated in the singlet ground state $^{60}$ and RASSCF calculations ${ }^{61}$ indicate that closed-shell singlet is the predominant electronic configuration for $\mathbf{2 a}$ (see Supplementary Methods). The calculated C-O stretching frequency for $\mathbf{2 a}$ is $1720 \mathrm{~cm}^{-1}$ (scaled by 0.95), which is higher than that found experimentally $\left[1673 \mathrm{~cm}^{-1}\left(2^{\text {Mes }}\right)\right.$ and $\left.1695 \mathrm{~cm}^{-1}\left(\mathbf{2}^{\mathrm{Xyl}}\right)\right]$. This is not unexpected, as it has been documented that calculations which assume a harmonic approximation may overestimate IR stretching frequencies ${ }^{38}$.
Labelling studies and mechanistic investigations. Reactions between $\mathbf{1}^{\text {Mes }}$ or $\mathbf{1}^{\mathrm{Xyl}}$ and ${ }^{13} \mathrm{CO}$ show that the squaraine molecules $\left(\mathbf{2}^{\mathrm{Mes}}\right.$ and $\mathbf{2}^{\mathrm{Xyl}}$ ) incorporate four $\mathrm{C}$ atoms [C49 to $\mathrm{C} 52$ $\left(2^{\mathrm{Mes}}\right)$ and $\mathrm{C} 13$ to $\left.\mathrm{C} 14\left(2^{\mathrm{Xyl}}\right)\right]$ from $\mathrm{CO}$ into the central $\mathrm{C}_{4} \mathrm{O}_{2}$ ring. This requires complete $\mathrm{C} \equiv \mathrm{O}$ bond cleavage and the formation of new $\mathrm{C}-\mathrm{C}$ bonds, which is significant as the reactions between $\mathrm{CO}$ and $\mathbf{1}^{\mathrm{Mes}}$ or $\mathbf{1}^{\mathrm{Xyl}}$ take place under ambient conditions in the absence of an external reducing agent. The reaction between $1^{\text {Mes }}$ and ${ }^{13} \mathrm{CO}$ generates $2^{\text {Mes_13 }} \mathrm{C}$, where the ${ }^{13} \mathrm{C}\left\{{ }^{1} \mathrm{H}\right\}$ NMR spectrum displays triplet resonances for the central ${ }^{13} \mathrm{C}_{4} \mathrm{O}_{2}$ ring $\left[\delta_{\mathrm{C}} 269.7 \mathrm{ppm}\left(\mathrm{t},{ }^{1} J(\mathrm{C}, \mathrm{C})=45 \mathrm{~Hz}, \mathrm{CO}\right), 177.3 \mathrm{ppm}\left(\mathrm{t},{ }^{1} J\right.\right.$ $(\mathrm{C}, \mathrm{C})=45 \mathrm{~Hz}, \quad \mathrm{CCO})]$. Furthermore, ${ }^{13} \mathrm{C},{ }^{13} \mathrm{C}-\mathrm{COSY}$ NMR (Supplementary Fig. 6) shows a correlation between these $\mathrm{C}$ atoms, providing further evidence that the four carbon atoms of the central ${ }^{13} \mathrm{C}_{4} \mathrm{O}_{2}$ ring must originate from ${ }^{13} \mathrm{CO}$. The solution IR spectrum of $2^{\text {Mes_13 }} \mathrm{C}$ displays an absorption at $1638 \mathrm{~cm}^{-1}$ (Fig. 2c). DFT calculations of $\mathbf{2 a}^{-13} \mathbf{C}$ predict a vibrational frequency $\left(1675 \mathrm{~cm}^{-1}\right)$ that is $37 \mathrm{~cm}^{-1}$ higher than that determined experimentally (Supplementary Table 3 ). However, the ratio of the calculated frequencies $\left({ }^{13} \mathrm{C} /{ }^{12} \mathrm{C}=0.974\right)$, compares well with that of the experimental values (0.979). Isolated samples of $2^{\text {Mes_13 }} \mathbf{C}$ contain a minor by-product that is observed as two doublets in the ${ }^{13} \mathrm{C}\left\{{ }^{1} \mathrm{H}\right\}$ NMR spectrum $\left[\delta_{\mathrm{C}} 193.6\left(\mathrm{~d},{ }^{1} J(\mathrm{C}, \mathrm{C})=\right.\right.$ $108 \mathrm{~Hz}, \mathrm{C}=\mathrm{C}=\mathrm{O}), 24.8\left(\mathrm{~d},{ }^{1} J(\mathrm{C}, \mathrm{C})=108 \mathrm{~Hz}, \mathrm{C}=\mathrm{C}=\mathrm{O}\right)$, see Supplementary Fig. 7], which are attributed to a ketene- or ketenyl-type intermediate in the formation of $\mathbf{2}^{\text {Mes }}$ and $\mathbf{2}^{\mathrm{Xyl}}$ 37,62.

To gain insight into the reaction between $\mathbf{1}^{\mathrm{Mes}}$ and $\mathrm{CO}$, the progress of the reaction was monitored by IR (Fig. 2a, b) and NMR spectroscopies. Initially, three new IR bands appeared $35 \mathrm{~min}$ after the addition of CO to the reaction mixture $(v=2097,2050$, $1978 \mathrm{~cm}^{-1}$ ). The band at $2097 \mathrm{~cm}^{-1}$ increased in intensity whilst the bands at 2050 and $1978 \mathrm{~cm}^{-1}$ decreased in intensity over the course of the reaction. The bands at 2050 and $1978 \mathrm{~cm}^{-1}$ are most likely associated with terminal Fe carbonyls ${ }^{63}$ and occur in a similar range to those of the $\mathrm{Fe}^{\mathrm{II}}$ carbonyl species, $\left(\eta^{2}-2,6-\mathrm{Dipp}_{2} \mathrm{C}_{6} \mathrm{H}_{3} \mathrm{CO}\right)_{2} \mathrm{Fe}(\mathrm{CO})_{2}, \quad\left(v=2000,1944 \mathrm{~cm}^{-1}\right)^{48}$, whilst the band at $2097 \mathrm{~cm}^{-1}$ is consistent with a ketene or ketenyl species $(\mathrm{C}=\mathrm{C}=\mathrm{O})$, which appear in the range 2080 to $2250 \mathrm{~cm}^{-1} 62$. The 
a

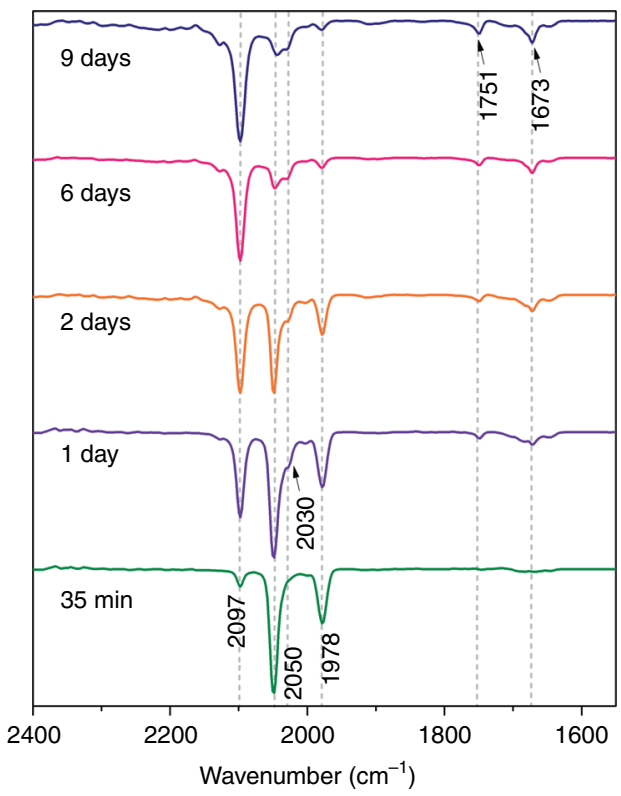

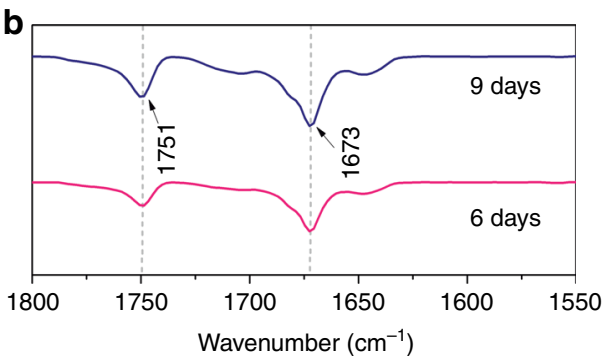

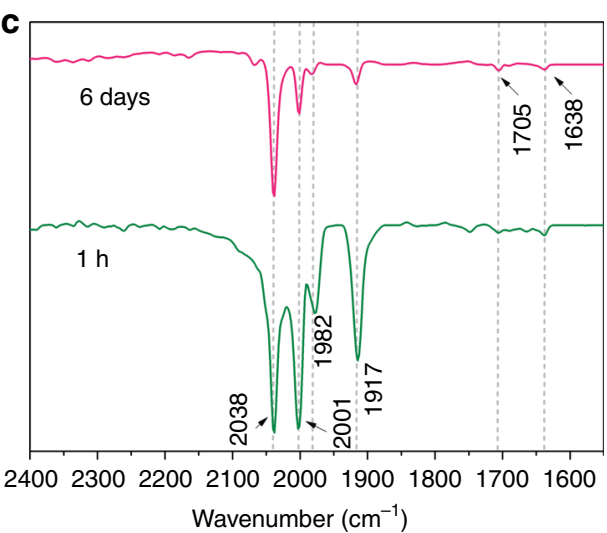

Fig. 2 IR spectroscopic monitoring of the reaction between $\mathbf{1}^{\text {Mes }}$ and carbon monoxide. a IR spectra in toluene at room temperature obtained from the reaction of $\mathbf{1}^{\text {Mes }}$ with $\mathrm{CO}$; an aliquot was taken from the reaction mixture at the indicated times, dried under vacuum for ca. $1 \mathrm{~h}$ and dissolved in toluene. b Zoom of a between 1800 and $1550 \mathrm{~cm}^{-1}$; spectra recorded at 6 days and 9 days. c IR spectra in toluene at room temperature obtained from the reaction of $\mathbf{1}^{\text {Mes }}$ with ${ }^{13} \mathrm{CO}$; an aliquot was taken from reaction mixture at the indicated times, dried under vacuum for ca. $1 \mathrm{~h}$ and dissolved in toluene

reaction between $\mathbf{1}^{\text {Mes }}$ and ${ }^{13} \mathrm{CO}$ was also monitored by IR spectroscopy (Fig. 2c) and features bands between $1638-2038 \mathrm{~cm}^{-1}$, all of which are shifted with respect to those observed in the analogous reaction between $\mathbf{1}^{\text {Mes }}$ and CO (Supplementary Table 1). Monitoring the reaction by ${ }^{1} \mathrm{H}$ and ${ }^{13} \mathrm{C}\left\{{ }^{1} \mathrm{H}\right\}$ NMR spectroscopy in $\mathrm{C}_{6} \mathrm{D}_{6}$ shows the disappearance of the peaks associated with $1^{\text {Mes }}$ immediately after the addition of $\mathrm{CO}$, followed by the appearance of $\mathbf{2}^{\text {Mes }}$ and paramagnetically shifted peaks after $19 \mathrm{~h}$. After $30 \mathrm{~h}$ crystals formed, which were determined to be a mixture of $\mathbf{2}^{\text {Mes }}$ and $3^{\text {Mes }}$ by X-ray diffraction. The formation of $\mathrm{Fe}(\mathrm{CO})_{5}$ was confirmed in the reaction between $\mathbf{1}^{\text {Mes }}$ or $\mathbf{1}^{\mathrm{Xyl}}$ and CO by IR and NMR spectroscopy, with bands at 2024 and $1999 \mathrm{~cm}^{-1}$ (Supplementary Fig. 15) ${ }^{64}$, and a singlet at $211 \mathrm{ppm}$ in the ${ }^{13} \mathrm{C}\left\{{ }^{1} \mathrm{H}\right\}$ NMR spectra.

To investigate further the influence of the aryl substituents on the reaction of $m$-terphenyl iron(II) complexes with $\mathrm{CO}$, a solution of $\left(2,6-\mathrm{Naph}_{2} \mathrm{C}_{6} \mathrm{H}_{3}\right)_{2} \mathrm{Fe}$ (THF) ( $\mathbf{1}^{\text {Naph}}$; Naph $\left.=1-\mathrm{C}_{10} \mathrm{H}_{7}\right)$ in $\mathrm{Et}_{2} \mathrm{O}$ was exposed to $\mathrm{CO}$. After stirring at room temperature overnight, the reaction was worked up to afford red crystals of the metallacyclic $\mathrm{Fe}^{\mathrm{II}}$ carbene $(\mathrm{CO}){ }_{3} \mathrm{Fe}\left[\mathrm{C}\left(2,6-\mathrm{Naph}_{2} \mathrm{C}_{6} \mathrm{H}_{3}\right) \mathrm{OC}(\mathrm{O})\right.$ (2,6- $\left.\mathrm{Naph}_{2} \mathrm{C}_{6} \mathrm{H}_{3}\right)$ ] (4) that were suitable for X-ray diffraction measurements (Fig. 3). The solid-state structure of $\mathbf{4}$ exhibits an $\mathrm{Fe}^{\mathrm{II}}$ centre in a distorted square-pyramidal environment $\left(\tau_{5}=\right.$ 0.37 ). Compound 4 displays complex (see Supplementary Discussion and Supplementary Fig. 8) diamagnetic ${ }^{1} \mathrm{H}$ and ${ }^{13} \mathrm{C}\left\{{ }^{1} \mathrm{H}\right\}$ NMR spectra (Supplementary Figs. 9 and 10) and could represent an isolable analogue of an intermediate species in the reaction of

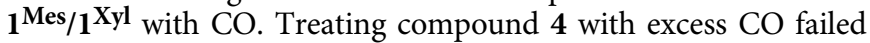
to yield any further reaction, even after prolonged heating $\left(80^{\circ} \mathrm{C}\right.$ for $14 \mathrm{~h}$, see Supplementary Methods).

It is possible to propose a pathway for the formation of the squaraines $\left(2^{\mathrm{Mes}}\right.$ and $\left.2^{\mathrm{Xyl}}\right)$ and $\mathrm{Fe}$ carboxylates ( $3^{\mathrm{Mes}}$ and $3^{\mathrm{Xyl}}$ ) from $\mathbf{1}^{\text {Mes }}$ and $\mathbf{1}^{\text {Xyl }}$ (Fig. 4) that is consistent with all spectroscopic data and the observation of compound 4 . The proposed

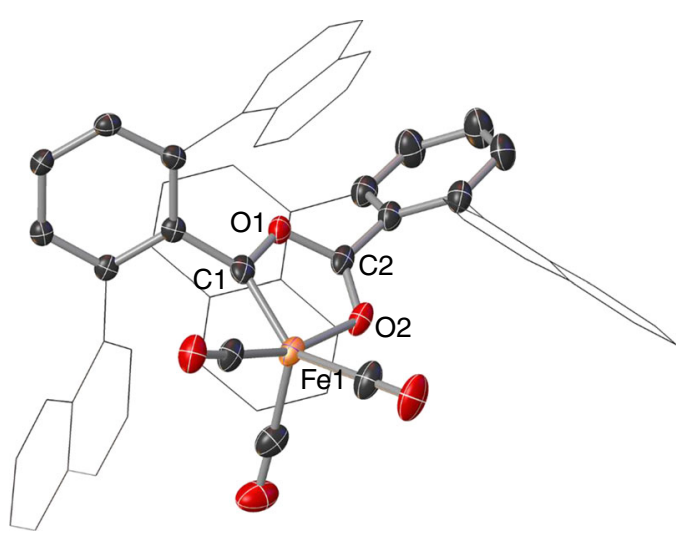

Fig. 3 Molecular structure of $\mathbf{4}$. Structure of $\mathbf{4}$ with anisotropic displacement ellipsoids set at $50 \%$ probability. Naphthyl groups shown as wireframe, hydrogen atoms and one molecule of $\mathrm{Et}_{2} \mathrm{O}$ solvent have been omitted for clarity. Selected bond distances $(\AA)$ for 4: Fe1-C1 1.840(3), $\mathrm{Fe} 1-\mathrm{O} 2$ 1.9572(18), Fe1-C3 1.830(3), Fe1-C4 1.753(3), Fe1-C5 1.849(3), C1-Fe1-O2 81.16(9)

mechanism also accounts for the observation (from ${ }^{13} \mathrm{C}$ labelling) that all carbons in the $\mathrm{C}_{4} \mathrm{O}_{2}$ ring derive from $\mathrm{CO}$.

First, $\mathrm{CO}$ coordinates to the $\mathrm{Fe}^{\mathrm{II}}$ centre in the diaryl complexes A, followed by 1,1-migratory insertion of $\mathrm{CO}$ into the $\mathrm{Fe}-\mathrm{C} \sigma$ bonds of the two $m$-terphenyl ligands to form an acyl intermediate of the type $\mathbf{B}$. A similar $\mathrm{Fe}^{\mathrm{II}}$ acyl complex has previously been observed in the reaction of $\left(2,6 \text { - } \mathrm{Dipp}_{2} \mathrm{C}_{6} \mathrm{H}_{3}\right)_{2} \mathrm{Fe}$ with $\mathrm{CO}^{48,49}$. Compound $\mathbf{B}$ then undergoes intramolecular $\mathrm{C}-\mathrm{O}$ bond formation via keto-carbene tautomerisation to the carbene intermediate $\mathbf{C}^{65,66}$. Attack of the carbonyl carbon by the $\mathrm{CO}^{-}$ unit forms the Fe carbene intermediate $(D)^{65,66}$, which is 

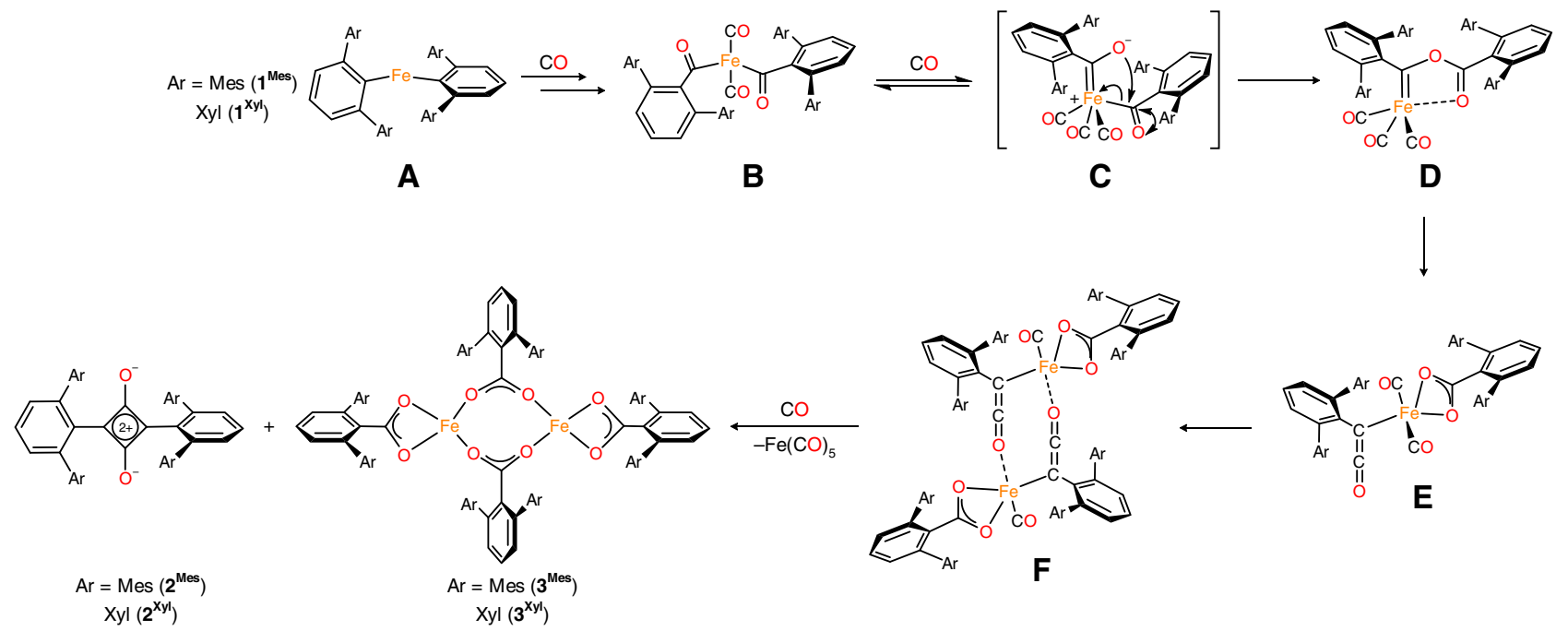

Fig. 4 Proposed pathway for the conversion of the iron(II) diaryls $\mathbf{1}^{\mathbf{M e s}}, \mathbf{1}^{\mathbf{X y l}}$ and $\mathbf{1}^{\mathbf{N a p h}}$ to $\mathbf{2}-\mathbf{4}$. Proposed mechanism for the reaction between $\mathbf{1}^{\mathbf{M e s}}, \mathbf{1}^{\mathbf{X y l}}$, and $\mathbf{1}^{\text {Naph }}$ and CO forming squaraines $\mathbf{2}^{\mathbf{M e s}}$ and $\mathbf{2}^{\mathbf{X y l}}$, carboxylate complexes $\mathbf{3}^{\mathbf{M e s}}$ and $\mathbf{3}^{\mathbf{X y l}}$ and carbene complex $\mathbf{4}$. In the case of $\mathrm{Ar}=$ naphthyl,

$\mathbf{D}=$ complex 4

analogous to the Fe carbene complex 4 . Species $\mathbf{D}$ may then react with $\mathrm{CO}^{44,62,67,68}$, to produce a ketenyl complex, with concomitant $\mathrm{CO}$ bond scission between the carbene $\mathrm{C}$ and carboxylate $\mathrm{O}$ to form intermediate $\mathbf{E}$. Species $\mathbf{E}$ then dimerises to form iron ketenyl carboxylate complex F, similar to those observed in the reaction of CO with low valent organolanthanide complexes $^{38,40}$. The coordinated ketene units may then dimerise in a $[2+2]$ cycloaddition reaction affording $2^{\mathrm{Mes}} / \mathbf{2}^{\mathrm{Xyl}}$ in an analogous manner to that for uncoordinated ketenes, which dimerise to form 1,3-cyclobutanediones ${ }^{62}$. The concomitant dimerisation of the $\mathrm{Fe}$-carboxylate units in $\mathbf{F}$ form the diiron carboxylate complexes $3^{\mathrm{Mes}} / 3^{\mathrm{Xyl}}$ and liberate $\mathrm{Fe}(\mathrm{CO})_{5}$.

Given the disparate reactivities of $1^{\text {Naph }}$ and $1^{\text {Xyl }} / 1^{\text {Mes }}$ on treatment with $\mathrm{CO}$, the mechanism proposed in Fig. 4 was probed by DFT, focusing on the conversion of $\mathbf{D}$ to $\mathbf{E}$ (see Supplementary Methods). For the xylyl substituted complex, the barrier to reaction $\left(\Delta^{\ddagger} G^{\circ}\right)$ is $+14.6 \mathrm{kcal} \mathrm{mol}^{-1}$, with a favourable $\Delta_{\mathrm{r}} G^{\circ}$ of $15.6 \mathrm{kcal} \mathrm{mol}^{-1}$. However, formation of the naphthyl substituted $\mathbf{E}$ has a larger energetic barrier $\left(\Delta^{\ddagger} G^{\circ}=22.8 \mathrm{kcal} \mathrm{mol}^{-1}\right)$ and is thermodynamically unfavourable $\left(\Delta_{\mathrm{r}} G^{\circ}=+19.6 \mathrm{kcal} \mathrm{mol}^{-1}\right)$. This striking difference is attributed to greater steric repulsion in $\mathbf{E}^{\mathrm{Naph}}$, where the CO ligands and ketene clash with the large naphthyl flanking groups (Supplementary Fig. 22). This result helps rationalise why $\mathbf{4}$ is an isolable complex, while the corresponding carbene is not observed in the reactions of $\mathbf{1}^{\text {Mes }}$ and $\mathbf{1}^{\mathrm{Xyl}}$ with CO, and highlights how the reactivity of these systems is heavily dependent on the nature of the flanking aryl groups.

This reactivity is rather remarkable when compared with other open shell iron(II) hydrocarbyls 45,46 and transition metal terphenyls ${ }^{48-50}$ which, although they undergo carbon monoxide coordination and migration, do not cleave $\mathrm{C} \equiv \mathrm{O}$ bonds. Presumably this is due to factors such as the overall ligand field strength, complex geometry, and steric effects, which we have shown (through theoretical calculations) are heavily dependent on the flanking aryl groups of the $m$-terphenyl ligands. The importance of steric effects in $\mathrm{CO}$ activation has been demonstrated previously ${ }^{19,69}$. Furthermore, our system contrasts with electron-rich systems such as the $\left[\left(\eta^{5}-\mathrm{C}_{5} \mathrm{H}_{5}\right) \mathrm{Fe}(\mathrm{CO})_{3}\right]^{+}$ model complex, which do not readily undergo carbonyl reduction and require the use of electrophiles to release homologated products $^{3}$.
Electrochemical investigations of squaraines. The electrochemical properties of $2^{\text {Mes }}$ were investigated by cyclic voltammetry, which revealed a reversible reduction process at $E_{1 /}$ ${ }_{2}=-0.79 \mathrm{~V}$ vs $\mathrm{Fc}^{+} / \mathrm{Fc}$ (Supplementary Fig. 13). This is significantly more anodic than typical squaraines, which possess reduction processes in the range of -1.40 to $-0.98 \mathrm{~V} \mathrm{vs} \mathrm{Fc}^{+} /$ $\mathrm{Fc}^{55,58}$. The reduction process is localised principally on the $\mathrm{C}_{4} \mathrm{O}_{2}$ ring in $2^{\mathrm{Mes}}$ (vide infra) and the difference in reduction potential is consistent with this moiety being electron deficient due to decreased conjugation with the aromatic rings. In addition, $\mathbf{2}^{\text {Mes }}$ displays an irreversible oxidation process at $E_{\mathrm{p}}{ }^{\mathrm{a}}=+0.48 \mathrm{~V}$ vs $\mathrm{Fc}^{+} / \mathrm{Fc}$ (Supplementary Fig. 14).

Monoanionic $\mathbf{2}^{\text {Mes- }}$ and $\mathbf{2}^{\mathrm{Mes} \bullet^{--}}{ }^{13} \mathrm{C}$ were prepared by the addition of $\mathrm{Cp}_{2} \mathrm{Co}\left(\mathrm{Cp}=\eta^{5}-\mathrm{C}_{5} \mathrm{H}_{5}\right)$ to a solution of $2^{\text {Mes }}$ or $\mathbf{2}^{\text {Mes_13 }} \mathrm{C}$ in $\mathrm{CH}_{2} \mathrm{Cl}_{2}$. The experimental X-band EPR spectra, along with the simulated spectra, are shown in Fig. 5. The spectra show hyperfine couplings to ${ }^{1} \mathrm{H}$ and ${ }^{13} \mathrm{C}$ centres and may be simulated using the spin Hamiltonian parameters shown in Supplementary Table 2. The room temperature Xband EPR spectrum of $2^{\mathrm{Xyl} \bullet-}$ in $\mathrm{CH}_{2} \mathrm{Cl}_{2}$ solution (generated from the addition of $\mathrm{Cp}_{2}$ Co to $2^{\mathrm{Xyl}}$ ) is shown in Supplementary Fig. 19, with simulation parameters in Supplementary Table 2. Unrestricted DFT calculations of the hyperfine coupling constants of $2 \mathbf{a}^{\bullet-}$ (Supplementary Table 4) show a close correspondence with those derived from the EPR simulations of $2^{\text {Mese- }}$ and are consistent with a spin density distribution (Supplementary Fig. 21) that lies across the central $\left\{\left(\mathrm{C}_{6} \mathrm{H}_{3}\right)_{2} \mathrm{C}_{4} \mathrm{O}_{2}\right\}$ core with little delocalisation onto the flanking aryl substituents.

\section{Discussion}

Two-coordinate iron(II) diaryl complexes promote the reductive cleavage and homologation of $\mathrm{CO}$ to yield $\left\{\mathrm{C}_{4} \mathrm{O}_{2}\right\}$ species at room temperature and atmospheric pressure, converting $\mathrm{C}_{1}$ feedstocks into useful organic molecules through a single first-row transition metal site. Unlike past work on $\mathrm{C}_{4}$ ring formation through homologation, these reactions proceed via $\mathrm{C} \equiv \mathrm{O}$ bond cleavage, and afford unusual squaraine species featuring broken conjugation. The observation of well-defined intermediates in this reaction, in addition to evidence from spectroscopy and isotopic labelling, allows us to rationalise the CO activation processes and 

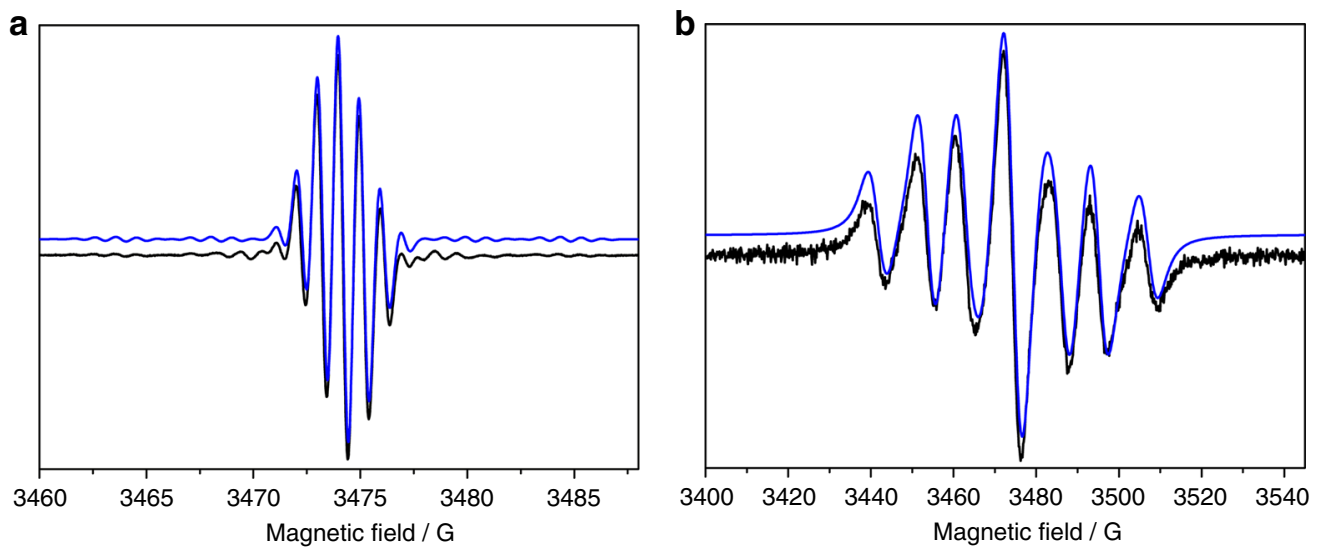

Fig. 5 Spectroscopic investigations of $\mathbf{2}^{\text {Mes }}$ with $\mathrm{Cp}_{2} \mathrm{Co}$ in $\mathrm{CH}_{2} \mathrm{Cl}_{2}$ at room temperature. a Experimental X-band EPR spectrum of $\mathbf{2}^{\text {Mese- }}$ (black trace) recorded as a fluid solution in $\mathrm{CH}_{2} \mathrm{Cl}_{2}$ at room temperature. The simulated spectrum is given in blue and parameters used for the simulation are listed in Supplementary Table 2. b Experimental X-band EPR spectrum of $\mathbf{2}^{\text {Mes }}{ }^{--}{ }^{13} \mathbf{C}$ (black trace) recorded as a fluid solution in $\mathrm{CH}_{2} \mathrm{Cl}_{2}$ at room temperature. The simulated spectrum is given in blue and parameters used for the simulation are listed in Supplementary Table 2

propose a reasonable mechanism that is in-line with experimental observations. Furthermore, this investigation provides additional insight into $\mathrm{CO}$ activation by transition metals, which is of relevance to a vast array of industrially important catalytic processes.

\section{Methods}

For synthetic details, analytical data, full descriptions of the methods and details of the computational calculations contained in this paper see Supplementary Information. For full synthetic procedures and analytical data for the compounds herein see Supplementary Methods. For a view of the single crystal X-ray structure for compounds $\mathbf{1}^{\mathrm{Xyl}}, \mathbf{2}^{\mathrm{Xyl}}, \mathbf{3}^{\mathrm{Xyl}}, \mathbf{1}^{\mathrm{Naph}}$ see Supplementary Figs. 1-4, respectively. For selected NMR spectra of the compounds in this article see Supplementary Figs. 5-7 and 9-11. Cyclic voltammograms of $2^{\text {Mes }}$ are found in the Supplementary Figs. 13 and 14. Additional IR spectra and reaction monitoring figures are found in Supplementary Figs 12 and 15-18. EPR parameters for the experimental and simulated EPR spectra for $\mathbf{2}^{\text {Mes-- }}, \mathbf{2}^{\text {Mes--13C }}$ and $\mathbf{2}^{\text {Xyl-- }}$ are given in Supplementary Table 2. Computational methods are outlined in the Supplementary Methods. Geometryoptimised co-ordinates of all computed structures are given in Supplementary Tables 5-13.

\section{Data availability}

X-ray crystallographic data for compounds $\mathbf{1}^{\mathrm{Xyl}}-\mathbf{4}$ are available free of charge from The Cambridge Crystallographic Data Centre (CCDC 1589889-1589895) via https://www. ccdc.cam.ac.uk/data_request/cif. All other data are available from the authors upon reasonable request.

Received: 30 April 2018 Accepted: 15 August 2018

Published online: 14 September 2018

\section{References}

1. Cavell, K. J. Recent fundamental studies on migratory insertion into metalcarbon bonds. Coord. Chem. Rev. 155, 209-243 (1996).

2. Jahangiri, H., Bennett, J., Mahjoubi, P., Wilson, K. \& Gu, S. A review of advanced catalyst development for Fischer-Tropsch synthesis of hydrocarbons from biomass derived syn-gas. Catal. Sci. Technol. 4, 2210-2229 (2014).

3. West, N. M., Miller, A. J. M., Labinger, J. A. \& Bercaw, J. E. Homogeneous syngas conversion. Coord. Chem. Rev. 255, 881-898 (2011).

4. Bodnar, T. et al. Aspects of homogeneous carbon monoxide fixation: selective conversion of two carbonyl ligands on $\left(\eta^{5}-\mathrm{C}_{5} \mathrm{H}_{5}\right) \mathrm{Fe}(\mathrm{CO})_{3}{ }^{+}$to $\mathrm{C} 2$ organic compounds. J. Am. Chem. Soc. 103, 2471-2472 (1981).

5. Bodnar, T., Coman, E., Menard, K. \& Cutler, A. Homogeneous reduction of ligated carbon dioxide and carbon monoxide to alkoxymethyl ligands. Inorg. Chem. 21, 1275-1277 (1982)

6. Crawford, E. J., Lambert, C., Menard, K. P. \& Cutler, A. R. The carbalkoxymethyl ligand on $\left(\eta-\mathrm{C}_{5} \mathrm{H}_{5}\right)(\mathrm{CO})\left[\mathrm{P}\left(\mathrm{OCH}_{3}\right)_{3}\right] \mathrm{FeCH}_{2} \mathrm{CO}_{2} \mathrm{CH}_{3}$ as a carbon monoxide-derived C2 template for generating C2 organic ligands and molecules. J. Am. Chem. Soc. 107, 3130-3139 (1985).

7. Cutler, A. R., Hanna, P. K. \& Vites, J. C. Carbon monoxide and carbon dioxide fixation: relevant $\mathrm{C} 1$ and $\mathrm{C} 2$ ligand reactions emphasizing $\left(\eta^{5}-\mathrm{C}_{5} \mathrm{H}_{5}\right) \mathrm{Fe}-$ containing complexes. Chem. Rev. 88, 1363-1403 (1988).

8. Davies, S. G., Hibberd, J. \& Simpson, S. J. Disproportionation of the iron carbonyl hydride $\left(\eta^{5}-\mathrm{C}_{5} \mathrm{H}_{5}\right) \mathrm{Fe}(\mathrm{CO}) \mathrm{H}\left(\mathrm{Ph}_{2} \mathrm{PCH}_{2} \mathrm{CH}_{2} \mathrm{PPh}_{2}\right)$ to the iron methyl $\left.\left(\eta^{5}-\mathrm{C}_{5} \mathrm{H}_{5}\right) \mathrm{FePh}_{2} \mathrm{PCH}_{2} \mathrm{CH}_{2} \mathrm{PPh}_{2}\right)$ Me. J. Chem. Soc. Chem. Commun. 1404-1405 (1982)

9. Bodnar, T. W. \& Cutler, A. R. Formation of a stable $\left(\eta^{2}-C, C\right)$ ketene compound dicarbonyl(cyclopentadienyl)keteneiron hexafluorophosphate $\left[\left(\mathrm{C}_{5} \mathrm{H}_{5}\right) \mathrm{Fe}(\mathrm{CO})_{2}\left(\mathrm{CH}_{2} \mathrm{CO}\right)^{+} \mathrm{PF}_{6}^{-}\right]$by carbonylation of an iron-methylidene complex. A novel entry into carbonyl-derived C2 chemistry. J. Am. Chem. Soc. 105, 5926-5928 (1983).

10. Bodnar, T. W., Crawford, E. J. \& Cutler, A. R. Transition organometallic mediated synthesis of a C3 malonic ester from carbon monoxide. Organometallics 5, 947-950 (1986).

11. Jian, Z. et al. $\mathrm{CO}^{-}$Reduction chemistry: reaction of a CO-derived formylhydridoborate with carbon monoxide, with carbon dioxide, and with dihydrogen. J. Am. Chem. Soc. 139, 6474-6483 (2017).

12. Matsuo, T. \& Kawaguchi, H. A synthetic cycle for $\mathrm{H}_{2} / \mathrm{CO}$ activation and allene synthesis using recyclable zirconium complexes. J. Am. Chem. Soc. 127, 17198-17199 (2005).

13. Wolczanski, P. T. \& Bercaw, J. E. On the mechanism of carbon monoxide reduction with zirconium hydrides. Acc. Chem. Res. 13, 121-127 (1980).

14. Watanabe, T., Ishida, Y., Matsuo, T. \& Kawaguchi, H. Reductive coupling of six carbon monoxides by a ditantalum hydride complex. J. Am. Chem. Soc. 131, 3474-3475 (2009).

15. Braunschweig, $\mathrm{H}$. et al. Metal-free binding and coupling of carbon monoxide at a boron-boron triple bond. Nat. Chem. 5, 1025-1028 (2013).

16. Wang, X. et al. Room-temperature reaction of carbon monoxide with a stable diarylgermylene. J. Am. Chem. Soc. 131, 6912-6913 (2009).

17. Suess, D. L. \& Peters, J. C. A CO-derived iron dicarbyne that releases olefin upon hydrogenation. J. Am. Chem. Soc. 135, 12580-12583 (2013).

18. Miller, A. J. M., Labinger, J. A. \& Bercaw, J. E. Homogeneous CO hydrogenation: ligand effects on the Lewis acid-assisted reductive coupling of carbon monoxide. Organometallics 29, 4499-4516 (2010).

19. Zhang, X.-X., Parks, G. F. \& Wayland, B. B. One-electron activation of CO by a rhodium(II) porphyrin bimetalloradical complex and concerted reactions of two (RhCO) ${ }^{*}$ units. J. Am. Chem. Soc. 119, 7938-7944 (1997).

20. Coffin, V. L., Brennen, W. \& Wayland, B. B. Thermodynamic studies of competitive adduct formation: single- and double-Insertion reactions of carbon monoxide with rhodium octaethylporphyrin dimer. J. Am. Chem. Soc 110, 6063-6069 (1988).

21. Erker, G., Czisch, P., Schlund, R., Angermund, K. \& Krüger, C. Reductive coupling of CO: formation of a 1:1 adduct of $\eta_{2}$-ketone- and enediolatocomplex upon carbonylation of bis(cyclopentadienyl)hafnacyclobutane. Angew. Chem. Int. Ed. 25, 364-365 (1986).

22. Sazama, G. T. \& Betley, T. A. Reductive coupling of CO templated by iron bound to the tris(pyrrolide)ethane scaffold. Organometallics 30, 4315-4319 (2011).

23. Fumiyuki, O. \& Akio, Y. Configurational product control in reactions of transand cis-dialkylbis(tertiary phosphine)palladium(II) with carbon monoxide. 
Evidence supporting an alkyl migration mechanism in $\mathrm{CO}$ insertion into Pd-C bond. Chem. Lett. 10, 289-292 (1981).

24. Toreki, R., LaPointe, R. E. \& Wolczanski, P. T. CO Hydrogenation, Deoxygenation, and C-C coupling promoted by $\left[(\text { silox }) \mathrm{TaH}_{2}\right]_{2}$. J. Am. Chem. Soc. 109, 7558-7560 (1987).

25. Kurogi, T., Ishida, Y., Hatanaka, T. \& Kawaguchi, H. Reduction of carbon monoxide by a tetrakis(aryloxide)diniobium complex having four bridging hydrides. Dalton. Trans. 42, 7510-7513 (2013).

26. Miller, R. L. et al. Syntheses, carbonylations, and dihydrogen exchange studies of monomeric and dimeric silox (tert- $\mathrm{Bu}_{3} \mathrm{SiO}^{-}$) hydrides of tantalum: structure of $\left[(\text { silox })_{2} \mathrm{TaH}_{2}\right]_{2}$. J. Am. Chem. Soc. 115, 5570-5588 (1993).

27. Tsoureas, N., Summerscales, O. T., Cloke, F. G. N. \& Roe, S. M. Steric effects in the reductive coupling of $\mathrm{CO}$ by mixed-sandwich uranium(III) complexes. Organometallics 32, 1353-1362 (2013).

28. Evans, W. J., Wayda, A. L., Hunter, W. E. \& Atwood, J. L. Organolanthanoid activation of carbon monoxide: single and multiple insertion of $\mathrm{CO}$ into t-butyl lanthanoid bonds; X-ray crystallographic identification of a new bonding mode for a bridging enedione diolate ligand formed by formal coupling of four CO molecules. J. Chem. Soc. Chem. Commun. 706-708 (1981).

29. Gardner, B. M. et al. Homologation and functionalization of carbon monoxide by a recyclable uranium complex. Proc. Natl Acad. Sci. USA 109, 9265-9270 (2012).

30. Mansell, S. M., Kaltsoyannis, N. \& Arnold, P. L. Small molecule activation by uranium tris(aryloxides): experimental and computational studies of binding of $\mathrm{N}_{2}$, coupling of $\mathrm{CO}$, and deoxygenation insertion of $\mathrm{CO}_{2}$ under ambient conditions. J. Am. Chem. Soc. 133, 9036-9051 (2011).

31. Frey, A. S. et al. Mechanistic studies on the reductive cyclooligomerisation of $\mathrm{CO}$ by $\mathrm{U}(\mathrm{III})$ mixed sandwich complexes; the molecular structure of $[(\mathrm{U}(\eta-$ $\left.\left.\mathrm{C}_{8} \mathrm{H}_{6}\left\{S^{i} \operatorname{Pr} 3-1,4\right\}_{2}\right)\left(\eta-C p^{*}\right)\right]_{2}\left(\mu-\eta^{1}: \eta^{1}-\mathrm{C}_{2} \mathrm{O}_{2}\right)$. J. Am. Chem. Soc. 130, 13816-13817 (2008).

32. Summerscales, O. T., Cloke, F. G. N., Hitchcock, P. B., Green, J. C. \& Hazari, N. Reductive cyclotrimerization of carbon monoxide to the deltate dianion by an organometallic uranium complex. Science 311, 829-831 (2006).

33. Summerscales, O. T., Cloke, F. G. N., Hitchcock, P. B., Green, J. C. \& Hazari, N. Reductive cyclotetramerization of $\mathrm{CO}$ to squarate by a $\mathrm{U}(\mathrm{III})$ complex: the X-ray crystal structure of $\left[\left(\mathrm{U}\left(\eta-\mathrm{C}_{8} \mathrm{H}_{6}\left\{\mathrm{~S}^{i} \mathrm{Pr}_{3}-1,4\right\}_{2}\right)\left(\eta-\mathrm{C}_{5} \mathrm{Me}_{4} \mathrm{H}\right)\right] 2\left(\mu-\eta^{2}: \eta^{2}-\right.\right.$ $\mathrm{C}_{4} \mathrm{O}_{4}$ ). J. Am. Chem. Soc. 128, 9602-9603 (2006).

34. Wang, B., Luo, G., Nishiura, M., Luo, Y. \& Hou, Z. Cooperative trimerization of carbon monoxide by lithium and samarium boryls. J. Am. Chem. Soc. 139 , 16967-16973 (2017).

35. Christian, G., Stranger, R., Petrie, S., Yates, B. F. \& Cummins, C. C. Breaking chemistry's strongest bond: can three-coordinate $\left[\mathrm{M}\{\mathrm{N}(\mathrm{R}) \mathrm{Ar}\}_{3}\right]$ complexes cleave carbon monoxide? Chem. Eur. J. 13, 4264-4272 (2007).

36. Buss, J. A. \& Agapie, T. Four-electron deoxygenative reductive coupling of carbon monoxide at a single metal site. Nature 529, 72-75 (2016).

37. Majumdar, M. et al. Reductive cleavage of carbon monoxide by a disilenide. Angew. Chem. Int. Ed. 54, 8746-8750 (2015).

38. Evans, W. J., Lee, D. S., Ziller, J. W. \& Kaltsoyannis, N. Trivalent $\left[\left(\mathrm{C}_{5} \mathrm{Me}_{5}\right)_{2}(\mathrm{THF}) \mathrm{Ln}\right]_{2}\left(\mu-\eta^{2}: \eta^{2}-\mathrm{N}_{2}\right)$ complexes as reducing agents including the reductive homologation of $\mathrm{CO}$ to a ketene carboxylate, $\left(\mu-\eta^{4}-\mathrm{O}_{2} \mathrm{C}-\mathrm{C}=\mathrm{C}=\mathrm{O}\right)^{2-}$. J. Am. Chem. Soc. 128, 14176-14184 (2006).

39. LaPointe, R. E., Wolczanski, P. T. \& Mitchell, J. F. Carbon monoxide cleavage by $(\text { silox })_{3} \mathrm{Ta}\left(\right.$ silox $\left.=\mathrm{t}-\mathrm{Bu}_{3} \mathrm{SiO}^{-}\right)$. J. Am. Chem. Soc. 108, 6382-6384 (1986).

40. Evans, W. J., Grate, J. W., Hughes, L. A., Zhang, H. \& Atwood, J. L. Reductive homologation of $\mathrm{CO}$ to a ketenecarboxylate by a low-valent organolanthanide complex: synthesis and X-ray crystal structure of $\left[\left(\mathrm{C}_{5} \mathrm{Me}_{5}\right)_{4} \mathrm{Sm}_{2}\left(\mathrm{O}_{2} \mathrm{CCCO}\right)\right.$ (THF) ]2. J. Am. Chem. Soc. 107, 3728-3730 (1985).

41. Buss, J. A. \& Agapie, T. Mechanism of molybdenum-mediated carbon monoxide deoxygenation and coupling: mono- and dicarbyne complexes precede C-O bond cleavage and C-C bond formation. J. Am. Chem. Soc. 138, 16466-16477 (2016).

42. Okazaki, M., Ohtani, T., Takano, M. \& Ogino, H. Stepwise reduction of four carbonyl ligands in $\left(\eta^{5}-\mathrm{C}_{5} \mathrm{H}_{4} \mathrm{Me}\right)_{4} \mathrm{Fe}_{4}\left(\mu_{3}-\mathrm{CO}\right)_{4}$ to produce clusters containing $\mu_{3}$-methylidyne and/or acetylene ligands. Organometallics 23, 4055-4061 (2004).

43. Shima, T. \& Hou, Z. Hydrogenation of carbon monoxide by tetranuclear rare earth metal polyhydrido complexes. Selective formation of ethylene and isolation of well-defined polyoxo rare earth metal clusters. J. Am. Chem. Soc. 128, 8124-8125 (2006)

44. Neithamer, D. R. et al. Carbon monoxide cleavage by $(\text { silox })_{3} \mathrm{Ta}($ silox $=$ tert$\mathrm{Bu}_{3} \mathrm{SiO}^{-}$): physical, theoretical, and mechanistic investigations. J. Am. Chem. Soc. 111, 9056-9072 (1989).

45. Benito-Garagorri, D., Lagoja, I., Veiros, L. F. \& Kirchner, K. A. Reactivity of coordinatively unsaturated iron complexes towards carbon monoxide: to bind or not to bind? Dalton. Trans. 40, 4778-4792 (2011).

46. Mo, Z. \& Deng, L. Open-shell iron hydrocarbyls. Coord. Chem. Rev. 350, 285-299 (2017).
47. Carnahan, E. M., Protasiewicz, J. D. \& Lippard, S. J. 15 years of reductive coupling: what have we learned? Acc. Chem. Res. 26, 90-97 (1993).

48. Ni, C. \& Power, P. P. Insertion reactions of a two-coordinate iron diaryl with dioxygen and carbon monoxide. Chem. Commun. 5543-5545 (2009).

49. Lei, H. et al. An arene-stabilized cobalt(I) aryl: reactions with $\mathrm{CO}$ and NO. Inorg. Chem. 47, 10205-10207 (2008)

50. Gridley, B. M. et al. Low-coordinate cobalt(II) terphenyl complexes: precursors to sterically encumbered ketones. Chem. Commun. 48, 8910-8912 (2012).

51. Kays, D. L. \& Cowley, A. R. Monomeric, two-coordinate Mn, Fe and Co(II) complexes featuring 2,6-(2,4,6-trimethylphenyl)phenyl ligands. Chem. Commun. 10, 1053-1055 (2007)

52. Thomas, I. R. et al. WebCSD: the online portal to the Cambridge Structural Database. J. Appl. Cryst. 43, 362-366 (2010).

53. Yang, L., Powell, D. R. \& Houser, R. P. Structural variation in copper(I) complexes with pyridylmethylamide ligands: structural analysis with a new four-coordinate geometry index, $\tau_{4}$. Dalton Trans. 955-964 (2007).

54. Maltese, V. et al. Electro-optical properties of neutral and radical ion thienosquaraines. Chem. Eur. J. 22, 10179-10186 (2016).

55. Chen, G. et al. A series of squaraine dyes: effects of side chain and the number of hydroxyl groups on material properties and photovoltaic performance. Chem. Mater. 26, 1356-1364 (2014).

56. Maeda, T. et al. Conformational effect of symmetrical squaraine dyes on the performance of dye-sensitized solar cells. J. Mater. Chem. A 1, 1303-1309 (2013).

57. Mayerhöffer, U. \& Würthner, F. Cooperative self-assembly of squaraine dyes Chem. Sci. 3, 1215-1220 (2012).

58. Wang, S. et al. N,N-Diarylanilinosquaraines and their application to organic photovoltaics. Chem. Mater. 23, 4789-4798 (2011).

59. Kazmaier, P. M., Hamer, G. K. \& Burt, R. A. Conformational isomerism in squaraines: saturation transfer NMR studies on hydroxy squaraines. Can. J. Chem. 68, 530-536 (1990).

60. Kabatc, J., Kostrzewska, K., Jurek, K. \& Dobosz, R. \& Orzeł, Ł. 1,3-Bis (phenylamino)squaraine - photophysical and photochemical properties. Dyes Pigments 127, 179-186 (2016).

61. Malmqvist, P.-A., Rendell, A. \& Roos, B. O. The restricted active space selfconsistent-field method, implemented with a split graph unitary group approach. J. Phys. Chem. 94, 5411-5482 (1990).

62. Tidwell, T. T. Ketenes II 2nd edn (Wiley, New York, 2006).

63. Muthiah, K. A. T. et al. Mononuclear iron(II) dicarbonyls derived from NNS ligands - structural models related to a "pre-acyl" active site of mono-iron (Hmd) hydrogenase. Eur. J. Inorg. Chem. 2015, 1675-1691 (2015).

64. Bachler, V., Grevels, F.-W., Kerpen, K., Olbrich, G. \& Schaffner, K. Novel facet of carbonyliron-diene photochemistry: the $\eta^{4}$-s-trans isomer of the classical Fe $(\mathrm{CO})_{3}\left(\eta^{4}\right.$-s-cis-1,3-butadiene) discovered by time-resolved IR spectroscopy and theoretically examined by Density Functional Methods. Organometallics 22, 1696-1711 (2003).

65. Luart, D., le Gall, N., Salaün, J.-Y. \& Toupet, L. \& des Abbayes, H. Formation of metallacyclic iron carbene complexes via $\mathrm{C}-\mathrm{O}$ coupling between the two ligands of Bis(carbamoyl) intermediates. Organometallics 17, 2680-2682 (1998).

66. Le Gall, N., Luart, D., Salaün, J.-Y., Abbayes, H. D. \& Toupet, L. Mechanism of formation of the metallacyclic iron carbenes $(\mathrm{CO})_{3} \mathrm{Fe}\left[=\mathrm{C}\left(\mathrm{NR}_{2}\right) \mathrm{OC}(\mathrm{O}) \mathrm{NR}_{2}\right]$ formed by thermal evolution of bis carbamoyl complexes, characterization of $\eta^{2}$-carbamoyl intermediates. J. Organomet. Chem. 617-618, 483-494 (2001).

67. Grotjahn, D. B. et al. Controlled, reversible conversion of a ketene ligand to carbene and CO ligands on a single metal center. J. Am. Chem. Soc. 122, 5222-5223 (2000)

68. Calderazzo, F. et al. Zirconium(II)- and hafnium(II)-assisted reductive coupling of coordinated carbonyl groups leading to ketenylidene complexes of zirconium(IV) and hafnium(IV). Chem. Eur. J. 2, 412-419 (1996).

69. Wayland, B. B., Sherry, A. E. \& Coffin, V. L. Selective reductive coupling of carbon monoxide. J. Chem. Soc. Chem. Commun. 662-663 (1989).

\section{Acknowledgements}

This work was supported by the Engineering and Physical Sciences Research Council [grant number EP/R004064/1]; The Leverhulme Trust [grant number RPG-2014-317]; and the University of Nottingham. D.R. thanks Nottingham Trent University and the University of Nottingham for provision of time on the Hamilton and Minerva High Performance Computing Clusters. We also thank EPSRC UK National Mass Spectrometry Facility at Swansea University and Dr Mick Cooper at the University of Nottingham for mass spectrometry, Dr Adrienne Davis and Mr Kevin Butler at the University of Nottingham for VT NMR spectroscopy and Mr Stephen Boyer (London Metropolitan University) for elemental analyses. 


\section{Author contributions}

D.L.K. conceived and supervised the study. H.R.S., A.M.G., L.J.T., B.M.G. and T.J.B. performed the syntheses and spectroscopic studies. J.M., D.R. and L.J.T. performed the computational studies. E.S.D. performed the EPR spectroscopy and cyclic voltammetry. H.R.S., A.M.G., B.M.G. and T.J.B. performed the X-ray crystallographic measurements, and W.L. and A.J.B. provided crystallographic assistance and checked the crystallographic files. H.R.S., A.M.G., L.J.T., J.M. and D.L.K. wrote the paper. All authors discussed the results and commented on the manuscript.

\section{Additional information}

Supplementary Information accompanies this paper at https://doi.org/10.1038/s41467018-06242-w.

Competing interests: The authors declare no competing interests.

Reprints and permission information is available online at http://npg.nature.com/ reprintsandpermissions/
Publisher's note: Springer Nature remains neutral with regard to jurisdictional claims in published maps and institutional affiliations.

\section{(c) (1)}

Open Access This article is licensed under a Creative Commons Attribution 4.0 International License, which permits use, sharing, adaptation, distribution and reproduction in any medium or format, as long as you give appropriate credit to the original author(s) and the source, provide a link to the Creative Commons license, and indicate if changes were made. The images or other third party material in this article are included in the article's Creative Commons license, unless indicated otherwise in a credit line to the material. If material is not included in the article's Creative Commons license and your intended use is not permitted by statutory regulation or exceeds the permitted use, you will need to obtain permission directly from the copyright holder. To view a copy of this license, visit http://creativecommons.org/ licenses/by/4.0/.

(C) The Author(s) 2018 